\title{
High Inter- and Intratumoral Variability of Ki67 Labeling Index in Newly Diagnosed Prostate Cancer with High Gleason Scores
}

\author{
Tatjana Vlajnic ${ }^{a}$ Patrik Brunner ${ }^{a}$ Serenella Eppenberger-Castori ${ }^{a}$ \\ Cyrill A. Rentsch ${ }^{b}$ Tobias Zellweger ${ }^{c}$ Lukas Bubendorf ${ }^{a}$ \\ aPathology, Institute of Medical Genetics and Pathology, University Hospital Basel, University of Basel, Basel, \\ Switzerland; ' Department of Urology, University Hospital Basel, Basel, Switzerland; ' Division of Urology, St. Clara \\ Hospital, Basel, Switzerland
}

\section{Keywords}

Prostate cancer · Proliferation · Ki67

\begin{abstract}
Background: The majority of studies investigating the role of Ki67 labeling index (LI) in prostate carcinoma (PC) focused on localized PC treated radically, where $\mathrm{Ki} 67 \mathrm{LI}$ is regarded as a prognostic marker. The relevance of $\mathrm{Ki} 67$ in advanced PC remains largely unexplored. While Gleason score is still one of the best indicators of clinical outcomes in PC, differences in progression-free survival and overall survival in patients with high Gleason scores suggest that additional factors are involved in tumor progression. Understanding the underlying mechanisms could help to optimize treatment strategies for an individual patient. Here, we aimed to determine the inter-and intratumoral distribution of $\mathrm{Ki} 67 \mathrm{LI}$ in patients with PC with high Gleason scores and to correlate Ki67 LI with the status of ERG, PTEN, and Bcl-2. Methods: Immunohistochemistry for Ki67, ERG, PTEN, and Bcl-2 was performed on core needle biopsies from 112 patients with newly diagnosed PC Gleason score 8, 9, and 10. Results: Using a cutoff of $\geq 10 \%$, $17 / 112$ cases (15\%) had a homogeneously low and 95/112 cases (85\%) a high Ki67 LI. $41 \%$ of cases showed intratumor-
\end{abstract}

karger@karger.com www.karger.com/pat

Karger $\stackrel{\text { ' }}{5}$

GOPEN ACCESS
(C) 2021 The Author(s)

Published by S. Karger AG, Basel

This is an Open Access article licensed under the Creative Commons Attribution-NonCommercial-4.0 International License (CC BY-NC) (http://www.karger.com/Services/OpenAccessLicense), applicable to the online version of the article only. Usage and distribution for commercial purposes requires written permission. al heterogeneity containing areas with low and high proliferation. There was no association between Ki67 LI and ERG, PTEN, or BCl-2 status. Conclusions: Our data demonstrate major inter- and intratumoral variability of Ki67 LI in highgrade PC with a surprisingly low Ki67 LI in a subset of cases. Further studies are necessary to explore the molecular basis and potential clinical implications of a paradoxically low proliferation rate in high-grade PC.

(c) 2021 The Author(s)

Published by S. Karger AG, Basel

\section{Introduction}

Prostate cancer (PC) is the second most common cancer and the most common cause of cancer-related deaths in men worldwide [1]. The biological heterogeneity of PC is reflected in different clinical behavior, ranging from "low-risk" curable disease to "high-risk" lethal cancer.

Ki67 is a marker for proliferating cells that can be detected in cells during the active phases of the cell cycles (G1, S, G2, and M phase) [2]. The fraction of Ki67-positive tumor cells, so-called Ki67 labeling index (LI), is often used in different tumor types to estimate the aggressiveness and the clinical behavior of the tumor, as tumors
Correspondence to:

Tatjana Vlajnic, tatjana.vlajnic@usb.ch 
with a high Ki67 LI tend to grow faster and therefore behave more aggressively [3-8]. In neuroendocrine tumors of the gastrointestinal tract, $\mathrm{Ki} 67 \mathrm{LI}$ is used as a criterion for grading [9]. In addition, in breast cancer, Ki67 LI provides information in terms of response to chemotherapy and therefore serves as a predictive marker $[10,11]$.

Several studies have investigated the role of Ki67 LI as a prognostic marker in PC [12-14]. Although the results are somewhat inconsistent due to various biological and methodological factors, there is a correlation between high Ki67 LI and biochemical failure as well as high Gleason score/International Society of Urological Pathology (ISUP) Grade Group [13]. In our own studies, we identified Ki67 LI as an independent marker of adverse prognosis in PC [15-17]. Interestingly, we have observed a sometimes striking variation in the Ki67 LI in high-grade PC during our diagnostic practice. Although one would generally expect a high Ki67 LI in advanced, poorly differentiated PC, some Gleason pattern 4 and 5 (ISUP Grade Group 4 and 5) tumors show a paradoxically low proliferation. The meaning of this phenomenon has not yet been evaluated. It is possible that other mechanisms, for example, deregulation of the apoptosis rather than increased proliferation, are responsible for sustained tumor growth and progression [18].

PTEN has emerged as another promising prognostic marker in localized PC as well as a potential predictive marker in CRPC [19-21]. The status of ERG and PTEN protein expression might provide additional prognostic information in newly diagnosed PC. ERG expression as a result of TMPRSS2/ERG fusion is found in approximately $50 \%$ of organ-confined PCs but its role in tumor progression and its association with prognosis remains controversial [22]. Loss of PTEN expression has been associated with high-grade and advanced-stage PCs, particularly in cases harboring a TMPRSS2/ERG fusion and occurs in up to $40 \%$ of CRPC [19,23,24]. Additional data suggest that PTEN loss might be an early event and serve as molecular marker for rapid tumor progression $[25,26]$. There is limited data in the literature about Ki67 LI in correlation with PTEN and ERG status, most of them investigating their potential prognostic value in localized PC treated by radical prostatectomy $[27,28]$.

Finally, the oncoprotein $\mathrm{Bcl}-2$ contributes to tumor progression by inhibiting apoptosis [29]. Bcl-2 overexpression is associated with tumor progression and therapy resistance in PC $[30,31]$. Previous studies failed to show a significant association between Bcl-2 expression and Ki67 LI [32, 33]. The purpose of this study was to determine the prevalence of low and high Ki67 LI in newly diagnosed poorly differentiated PC with Gleason score 8, 9, and 10 (ISUP Grade Group 4 and 5) and to correlate Ki67 LI with the status of ERG, PTEN, and Bcl-2.

\section{Material and Methods}

\section{Patients and Tissue Samples}

We analyzed histological specimens from 112 patients (age range 51-90 years, median age 72 years, mean age 72 years) with PC Gleason Score 8, 9, and 10 (ISUP Grade Group 4 and 5), all with newly diagnosed (hormone naïve) PC between January 2006 and December 2016. Patients who had received androgen deprivation therapy prior to initial diagnostic biopsy were exempt from the study. Information about clinical stage was not available at the time of diagnosis. Specimens were selected by the amount of tumor material sufficient for analyses of several markers. We used cases with a minimum of 100 cells. All samples were core needle biopsies (CNB), retrieved from the archives of the Institute of Pathology Basel. This study was approved by the local Ethics Committee (reference EKNZ 2018-00509).

\section{Immunohistochemistry}

Tissue sections of $4 \mu \mathrm{m}$ were cut from formalin-fixed, paraffinembedded blocks and mounted on Superfrost slides. All immunohistochemical analyses were performed on the BenchMark Ultra automated immunostaining system using the OptiView detection system (Ventana Medical System Inc., Oro Valley, AZ, USA). Standard indirect immunoperoxidase procedures were used for the detection of Ki67 (clone MIB1, prediluted, Ref: IR626, Dako, Agilent, Santa Clara, USA), ERG (clone EPR3865, prediluted, Ref: 790-4576, Ventana Medical Systems, Inc.), PTEN (clone 138G6, 1:25 diluted, Ref: 9559, Cell Signaling, Danvers, MA, USA), and Bcl-2 (clone SP66, prediluted, Ref: 790-4604, Ventana Medical Systems, Inc.). DAB was used as chromogen, and counterstaining was performed with hematoxylin.

All samples were evaluated by a pathologist (T.V.) experienced in genitourinary pathology.

Proliferation (Ki67 LI) was estimated by semiquantitative eyeballing and scored from $0 \%$ to $100 \%$. Nuclear staining of any intensity in tumor cells was considered positive. A cutoff of $\geq 10 \%$ was used to define low and high Ki67 LI. Depending on the distribution of Ki67-positive cells, tumors were further designated as homogeneous or heterogeneous (containing both low and high proliferation areas). In heterogeneous cases, Ki67 LI was estimated in the areas with the highest density of Ki67-positive cells.

For ERG, nuclear staining of any intensity in tumor cells was considered positive, as previously reported [34]. The percentage of positive tumor cells was estimated and scored from $0 \%$ to $100 \%$. ERG staining of endothelial cells within the specimens served as internal positive control.

Loss of PTEN expression was considered only in tumor cells without any cytoplasmic or nuclear positivity, according to previously published evaluation criteria [35]. The percentage of completely negative tumor cells was estimated and scored from $0 \%$ to $100 \%$. Any percentage of completely negative tumor cells was considered loss of PTEN expression.

Bcl-2 expression was assessed using the $\mathrm{H}$-score: intensity of staining on a scale of 0 (no staining), 1 + (weak staining), $2+$ (mod- 

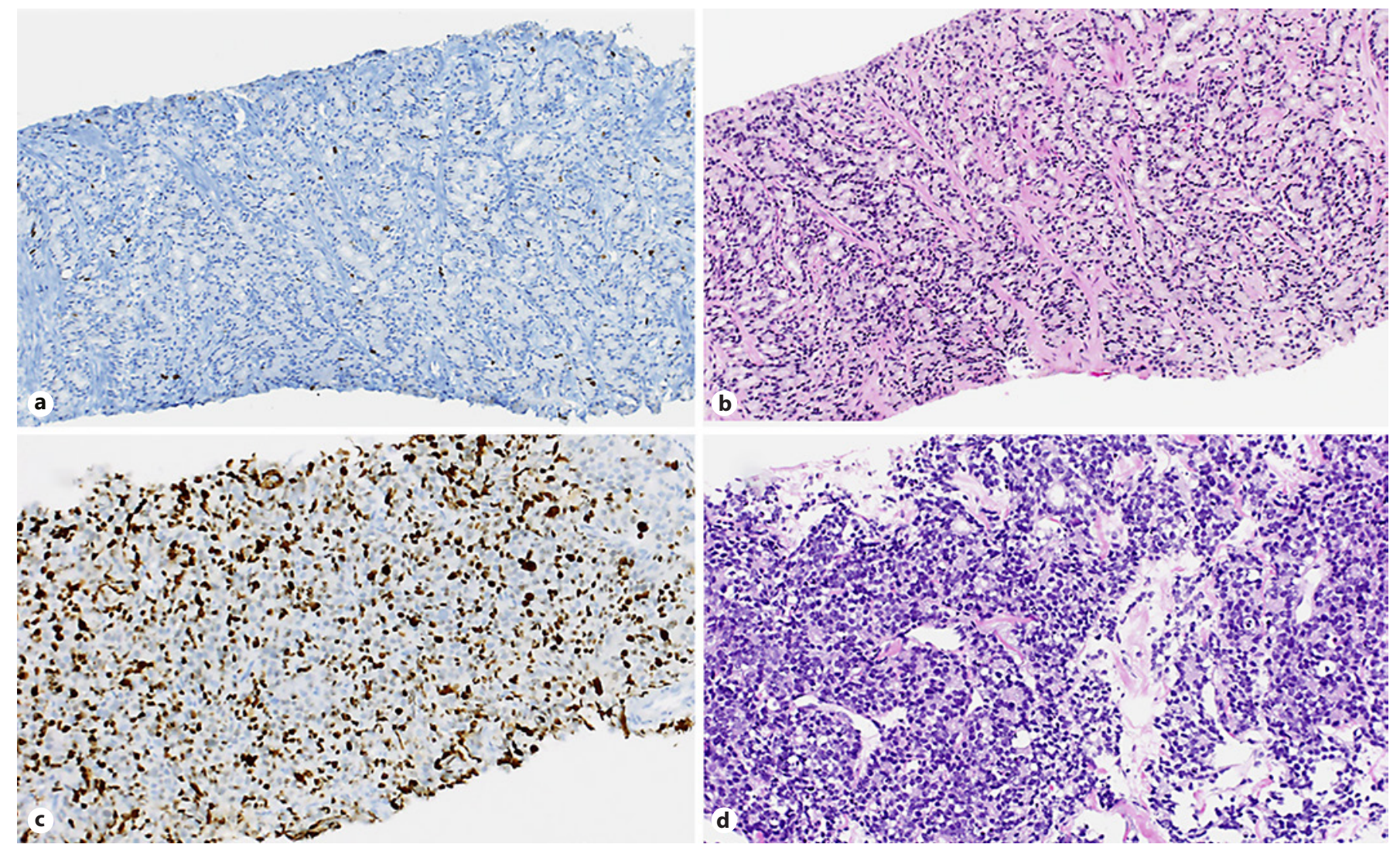

Fig. 1. a, b Gleason $8(4+4)$, ISUP Grade Group 4 prostate carcinoma with a homogeneously low Ki67 LI $(<5 \%)$ and corresponding morphology, H\&E. c, d Gleason $9(4+5)$, ISUP Grade Group 5 prostate carcinoma with a homogeneously high Ki67 LI (30\%) and the corresponding morphology, H\&E (a-d magnification $\times 200)$. LI, labeling index.

erate staining), and $3+$ (strong staining) multiplied by the percentage of positive tumor cells [32]. Bcl-2 staining of basal cells in benign prostatic glands within the specimens served as internal positive control.

\section{Data Analysis}

Association between Ki67 LI, ERG, PTEN, and Bcl-2 status were calculated by means of Fisher's exact test or $\chi^{2}$ test depending on the number of observations. Correlation coefficients were calculated according to Spearman. All $p$ values were 2 sided and considered significant when $p<0.05$. Analyses were conducted on $\mathrm{R}$ (Version 3.4.1 [2017-06-30] and higher, www.r-project.org).

\section{Results}

\section{Ki67 LI}

In total, Ki67 LI showed a range of $2.5 \%-65 \%$ with a mean of $18 \%$, and a median of $17.5 \%$. Using a cutoff of $\geq 10 \%, 17 / 112$ cases (15\%) had a low and 95/112 cases (85\%) had a high Ki67 LI (Fig. 1). When further divided according to heterogeneity, there were 17 cases with homogeneously low Ki67 LI and 43/95 cases (45\%) with high Ki67 LI, 13 of which showed a range within the high proliferation areas from $10 \%$ to $45 \% .39 / 95$ cases (41\%) showed intratumoral heterogeneity containing areas with both low and high proliferation (Fig. 2). For further analyses, Ki67 LI was dichotomized and a heterogeneous case containing any percentage of high proliferation areas (i.e., $\geq 10 \%$ Ki67 LI) was defined as high Ki67 LI.

\section{Ki67 LI and ERG}

ERG immunohistochemistry was available in 100/112 cases (Fig. 3). Of those, 62 cases (62\%) were negative and 38 cases $(38 \%)$ were positive for ERG (31 cases homogeneously positive and 7 cases heterogeneously positive with a range of $10-90 \%$ of positive cells). There was no significant association between Ki67 LI and ERG positivity (Fisher's Exact test: $p=0.558)$. Also, no dependency was observed between the heterogeneity of these 2 factors $(p=0.716)$. 


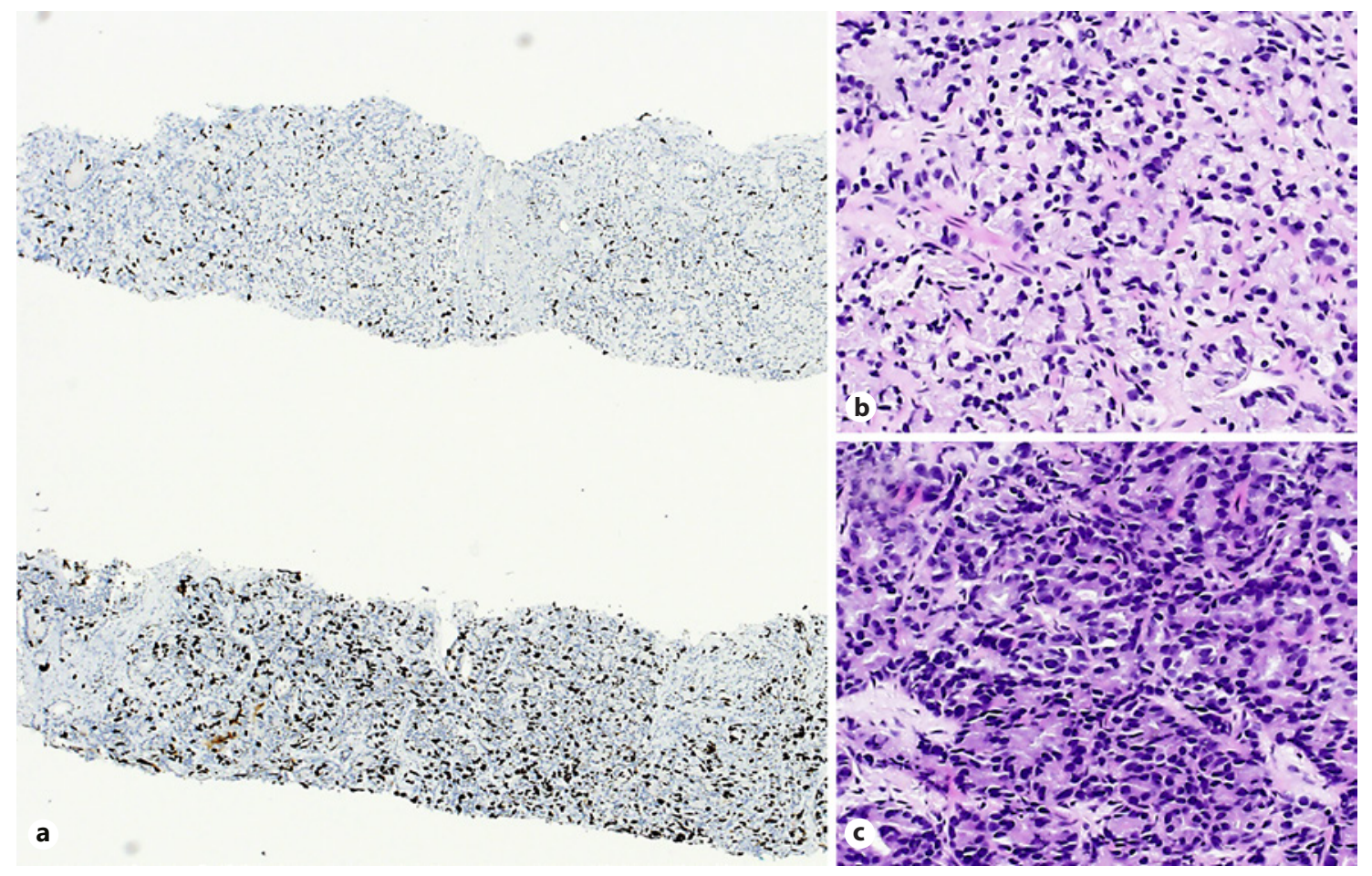

Fig. 2. a-c Gleason $8(4+4)$, ISUP Grade Group 4 prostate carcinoma with a heterogeneous Ki67 LI containing areas with both low (top left) and high (bottom left) proliferation areas and the corresponding morphology, $\mathrm{H} \& \mathrm{E}$ (a-c magnification $\times 200)$. LI, labeling index.

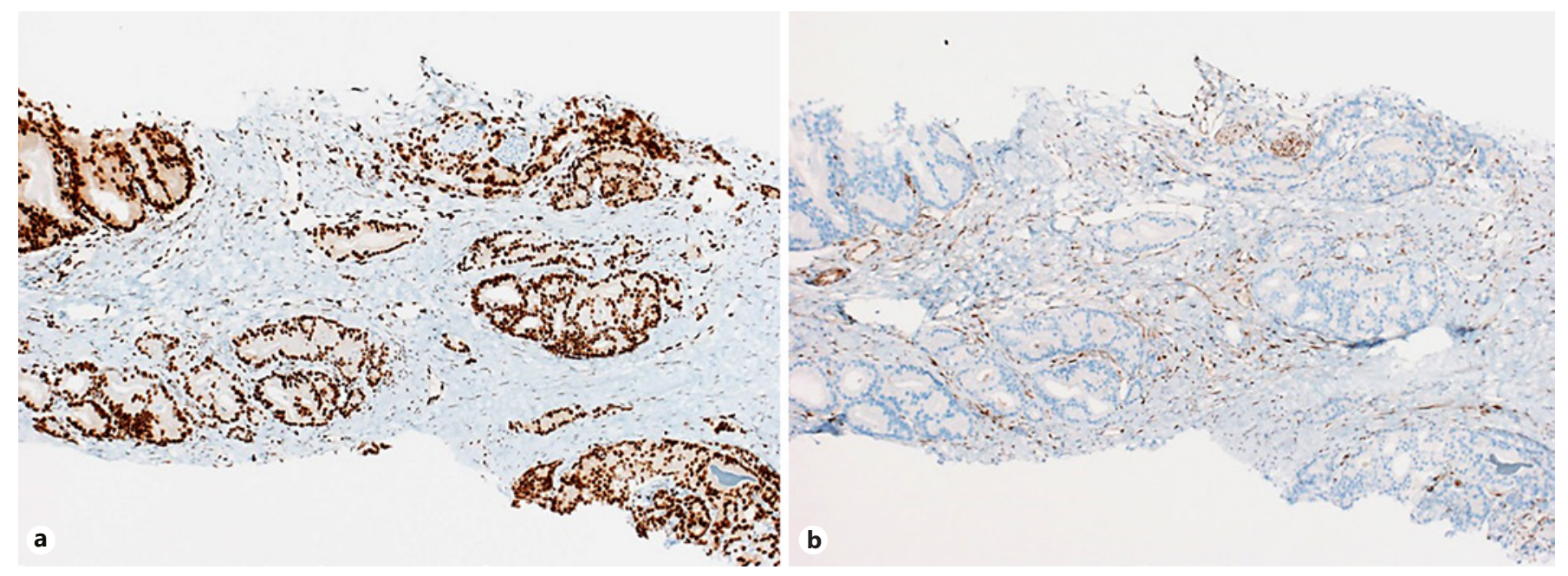

Fig. 3. a Gleason $8(4+4)$, ISUP Grade Group 4 prostate carcinoma with homogeneous positivity for ERG. b Complete loss of PTEN expression (a, b magnification $\times 200)$.

\section{Ki67 LI and PTEN}

PTEN immunohistochemistry was available in 100/112 cases (Fig. 3). Of those, 53 cases (53\%) showed preserved PTEN expression and 47 cases (47\%) showed loss of PTEN expression (18 cases with a complete loss and 29 cases with heterogenous/subclonal loss with a range of 5-95\%). There was no significant association between Ki67 LI and PTEN loss (Fisher's exact test: $p=0.779$ ). Also, no dependency was observed between the heterogeneity of these 2 factors $(p=0.251)$. 


\section{Ki67 LI and Bcl-2}

Bcl-2 immunohistochemistry was available in 100/112 cases. Of those, 44 cases (44\%) were negative and 56 cases $(56 \%)$ were positive for $\mathrm{Bcl}-2$ ( $\mathrm{H}$-score range $0-270$, median 5, mean 31.3). There was no significant association between Ki67 LI and Bcl-2 expression (Fisher's exact test: $p=0.574)$. No differences were observed when comparison of all variables was made quantitatively (results not shown).

\section{Discussion}

Numerous studies have shown that Ki67 LI is an independent predictor of recurrence and progression in localized PC [12-14]. Moreover, high Ki67 LI has been associated with higher Gleason scores/ISUP Grade Groups $[12,14,15,36]$. In this study, we aimed to determine the prevalence of low and high Ki67 LI in newly diagnosed PC with high Gleason scores/ISUP Grade Groups. According to the current ISUP grading system, Gleason scores 8, 9, and 10, that is, Grade Groups 4 and 5, respectively, define high-risk PC with potentially aggressive clinical behavior [37]. Our cohort represents newly diagnosed, untreated, hence hormone-naïve PC at an advanced stage or with a high risk of progression. As expected, the vast majority of the cases $(85 \%)$ showed a high Ki67 LI, 59\% of which had a homogeneously high Ki67 LI and 41\% had areas of intratumoral heterogeneity with both high and low proliferation. Interestingly, we have observed a homogeneously low Ki67 LI (Ki67 LI $2.5-7.5$ ) in $15 \%$ of our patients, which appears to contradict the general assumption that a high Gleason score/ ISUP Grade Group and tumor aggressiveness are reflected in a high proliferation rate in PC with intact AR signaling.

In this study, we used $\geq 10 \%$ as threshold for high Ki67 LI. However, Ki67 LI being a continuous variable, it is impossible to draw a clear line between low and high and inevitably there is a grey zone of intermediate values, as previously discussed [38]. Based on our observation during routine diagnostic practice, Ki67 LI in PC usually does not exceed $15 \%$ and only rarely reaches levels above $30 \%$. Thus, the intermediate grey zone appears to lie around $10 \%$. In fact, only $16 / 95$ cases (17\%) with high Ki67 LI in this study had a Ki67 LI of 10\%-14.9\%, whereas the majority (61/95 cases, $64 \%$ ) had a Ki67 LI between $15 \%$ and $25 \%$, and $18 / 95$ cases (18\%) had a Ki67 LI $>25 \%$. In a meta-analysis conducted on 21 studies reporting association of Ki67 and prognosis in localized, radically treated
PC, the mean Ki67 of $6.14 \%$ [13]. This is significantly lower than the mean Ki67 LI of 18\% in the present study, which is not surprising considering that our cohort consists of PC with high Gleason scores/ISUP Grade Group only.

The variations in reported Ki67 LI values in the literature are most likely due to differences in methodological approaches. There are several factors that can influence assessment of Ki67 LI in PC. Apart from the already mentioned lack of consensus for the optimal cutoff values, the choice of the scoring method (automated digital analysis, counting, or semiquantitative eyeballing) has an influence, especially in terms of interobserver variability. Moreover, Ki67 LI has been variably determined on radical prostatectomy specimens, $\mathrm{CNB}$, and tissue microarrays, all of them differently reflecting biological intratumoral heterogeneity. Since patients with newly diagnosed advanced PC usually are treated with systemic therapy only, CNB might be the only tissue available for prognostic and predictive marker testing. In this scenario, a certain degree of intratumoral heterogeneity is unavoidable. In our study cohort, only $18 \%(21 / 112)$ of patients had a radical prostatectomy. Hence, a comparison of Ki67 LI intratumoral heterogeneity between CNB and the corresponding prostatectomy specimen was not possible.

Some of the challenges regarding the assessment of Ki67 LI have already been addressed in other tumor types such as breast cancer, where Ki67 LI has become an integral part of the routine diagnostic work-up [10, 39]. Following the current recommendations in breast cancer, it appears most meaningful to define the values for high and low Ki67 LI for each laboratory individually [40, 41].

The observation of high inter- and intratumoral variation of Ki67 LI is surprising. Conceptually, one would expect a high proliferative activity throughout high-grade PC with Gleason Scores 8-10 (ISUP Grade Groups 4 and 5 ) as they are supposed to grow and progress rapidly. The presence of concomitant intratumoral areas with low and high Ki67 despite homogenous morphology suggests molecular heterogeneity. This could be explained with dynamic and geographically restricted transcriptional regulation of pathways that regulate cell proliferation and tumor growth. To better understand the underlying mechanisms for the observed inter- and intratumoral variation in Ki67 LI, we explored the association of Ki67 LI with 2 selected markers involved in pathways commonly altered in PC.

$\mathrm{Bcl}-2$ is an oncoprotein known to promote tumor growth and progression by inhibiting apoptosis [29]. We
78

Pathobiology 2022;89:74-80 DOI: $10.1159 / 000519007$
Vlajnic/Brunner/Eppenberger-Castori/ Rentsch/Zellweger/Bubendorf 
hypothesized that tumor growth in areas with low Ki67 LI is maintained by increased cell survival due to impaired apoptosis. In our series, $56 \%$ were positive for Bcl2 . However, there was no significant association between Ki67 LI and Bcl-2 expression, which is in line with previous data from early stage PC $[32,33]$. Therefore, our data provide no evidence that apoptosis inhibition by Bcl-2 overexpression could make up for a low proliferation rate in these tumors. Loss of PTEN function resulting in activation of the PI3K-AKT (phosphoinositide 3-kinaseRAC-alpha serine/threonine-protein kinase) pathway has been associated with worse prognosis in localized PC [19]. In line with previous reports [19], PTEN loss was found in a high proportion of PC (47\%) in our study. However, there was no association of Ki67 LI with PTEN loss or ERG expression.

Collectively, abnormal Bcl-2 or PTEN expression cannot provide insights into the reasons for Ki67 LI heterogeneity in high-grade PC. Comprehensive transcriptional profiling of tumor areas with low and high Ki67 LI would be needed to study the complexity of dynamic and regional growth regulation in PC. Such studies would require fresh tumor tissue.

We acknowledge that this study has certain limitations. Due to lack of systematic clinical data, it was not possible to determine the impact of Ki67 LI variability on clinical outcome. Furthermore, the analysis and correlation of only 2 other markers (PTEN and Bcl-2) does by far not reflect the molecular complexity of cancer. To appropriately address this question, comprehensive expression profiling analyses would be needed, requiring fresh tumor tissue samples. However, the actual purpose of this study was to determine the prevalence of high and low Ki67 in high-grade PC.

\section{Conclusion}

In conclusion, we have shown that a subset of newly diagnosed advanced PC with high Gleason scores/ISUP Grade Group show an apparently paradoxically low Ki67 LI, whereas the majority has a variably high Ki67 LI with significant intratumoral heterogeneity. The underlying mechanisms for these differences in proliferation yet need to be elucidated but it is very likely that various pathways are involved in promoting tumor growth and progression in high-risk PC. Further studies are needed to validate the role of Ki67 LI as a potential prognostic and predictive marker in newly diagnosed high-grade PC.

\section{Acknowledgements}

We thank Michèle Baumann, Petra Hirschmann, Luigi Costa, Viola Paradiso, and Luca Roma for excellent support, and Tobias Eichenberger, Gianfranco Mattarelli, and Helge Seifert for providing biopsies and patient care.

\section{Statement of Ethics}

This study was approved by the local Ethics Committee of Central and Northwestern Switzerland (reference EKNZ 2018-00509). Written informed consent was not required for this retrospective study.

\section{Conflict of Interest Statement}

Lukas Bubendorf is an Editorial Board member of the journal. The other authors have no conflicts of interest to declare.

\section{Funding Sources}

This project has been financially supported by Sanofi.

\section{Author Contributions}

T.V. and L.B. designed the study. T.V. wrote the manuscript. P.B., S.E.C., C.A.R., T.Z., and L.B. contributed equally to revisions of this work. All authors performed the collection of data. T.V. evaluated immunohistochemical result. S.E.C. performed statistical analysis. All authors critically read and approved the final manuscript.

\section{Data Availability Statement}

All data generated or analysed during this study are included in this article. Further enquiries can be directed to the corresponding author.

References

1 Torre LA, Bray F, Siegel RL, Ferlay J, LortetTieulent J, Jemal A. Global cancer statistics, 2012. CA Cancer J Clin. 2015 Mar;65(2):87108.

2 Scholzen T, Gerdes J. The Ki-67 protein: from the known and the unknown. J Cell Physiol. 2000 Mar;182(3):311-22.

3 Miller TP, Grogan TM, Dahlberg S, Spier CM, Braziel RM, Banks PM, et al. Prognostic significance of the Ki-67-associated proliferative antigen in aggressive non-Hodgkin's lymphomas: a prospective Southwest Oncology Group trial. Blood. 1994 Mar 15;83(6):14606. 
4 Munstedt K, von Georgi R, Franke FE. Correlation between MIB1-determined tumor growth fraction and incidence of tumor recurrence in early ovarian carcinomas. Cancer Invest. 2004;22(2):185-94.

5 Dziegiel P, Salwa-Zurawska W, Zurawski J, Wojnar A, Zabel M. Prognostic significance of augmented metallothionein (MT) expression correlated with Ki-67 antigen expression in selected soft tissue sarcomas. Histol Histopathol. 2005 Jan;20(1):83-9.

6 Johannessen AL, Torp SH. The clinical value of Ki-67/MIB-1 labeling index in human astrocytomas. Pathol Oncol Res. 2006;12(3): $143-7$.

7 Kankuri M, Söderström KO, Pelliniemi TT, Vahlberg T, Pyrhönen S, Salminen E. The association of immunoreactive p53 and Ki-67 with T-stage, grade, occurrence of metastases and survival in renal cell carcinoma. Anticancer Res. 2006 Sep-Oct;26(5B):3825-33.

8 Inwald EC, Klinkhammer-Schalke M, Hofstadter F, Zeman F, Koller M, Gerstenhauer $\mathrm{M}$, et al. Ki-67 is a prognostic parameter in breast cancer patients: results of a large population-based cohort of a cancer registry. Breast Cancer Res Treat. 2013 Jun;139(2):539-52.

9 Kloppel G. Neuroendocrine neoplasms: dichotomy, origin and classifications. Visc Med. 2017 Oct;33(5):324-30.

10 Yerushalmi R, Woods R, Ravdin PM, Hayes MM, Gelmon KA. Ki67 in breast cancer: prognostic and predictive potential. Lancet Oncol. 2010 Feb;11(2):174-83.

11 Tao M, Chen S, Zhang X, Zhou Q. Ki-67 labeling index is a predictive marker for a pathological complete response to neoadjuvant chemotherapy in breast cancer: a meta-analysis. Medicine. 2017 Dec;96(51):e9384.

12 Tretiakova MS, Wei W, Boyer HD, Newcomb LF, Hawley S, Auman H, et al. Prognostic value of Ki67 in localized prostate carcinoma: a multi-institutional study of $>1,000$ prostatectomies. Prostate Cancer Prostatic Dis. 2016 Sep;19(3):264-70.

13 Berlin A, Castro-Mesta JF, Rodriguez-Romo L, Hernandez-Barajas D, González-Guerrero JF, Rodríguez-Fernández IA, et al. Prognostic role of Ki-67 score in localized prostate cancer: a systematic review and meta-analysis. Urol Oncol. 2017 Aug;35(8):499-506.

14 Kammerer-Jacquet SF, Ahmad A, Møller H, Sandu H, Scardino P, Soosay G, et al. Ki-67 is an independent predictor of prostate cancer death in routine needle biopsy samples: proving utility for routine assessments. Mod Pathol. 2019 Sep;32(9):1303-9.

15 Bubendorf L, Sauter G, Moch H, Schmid HP, Gasser TC, Jordan P, et al. Ki67 labelling index: an independent predictor of progression in prostate cancer treated by radical prostatectomy. J Pathol. 1996 Apr;178(4):437-41.

16 Bubendorf L, Tapia C, Gasser TC, Casella R, Grunder B, Moch H, et al. Ki67 labeling index in core needle biopsies independently predicts tumor-specific survival in prostate cancer. Hum Pathol. 1998 Sep;29(9):949-54.
17 Zellweger T, Günther S, Zlobec I, Savic S, Sauter $\mathrm{G}$, Moch $\mathrm{H}$, et al. Tumour growth fraction measured by immunohistochemical staining of Ki67 is an independent prognostic factor in preoperative prostate biopsies with small-volume or low-grade prostate cancer. Int J Cancer. 2009 May 1;124(9):2116-23.

18 Kim JH, Lee H, Shin EA, Kim DH, Choi JB, Kim SH. Implications of Bcl-2 and its interplay with other molecules and signaling pathways in prostate cancer progression. Expert Opin Ther Targets. 2017 Sep;21(9):911-20.

19 Jamaspishvili T, Berman DM, Ross AE, Scher HI, De Marzo AM, Squire JA, et al. Clinical implications of PTEN loss in prostate cancer. Nat Rev Urol. 2018 Apr;15(4):222-34.

20 Rescigno P, Lorente D, Dolling D, Ferraldeschi R, Rodrigues DN, Riisnaes $\mathrm{R}$, et al. Docetaxel treatment in PTEN- and ERG-aberrant metastatic prostate cancers. Eur Urol Oncol. 2018 May;1(1):71-7.

21 Turnham DJ, Bullock N, Dass MS, Staffurth JN, Pearson HB. The PTEN conundrum: how to target PTEN-deficient prostate cancer. Cells. 2020 Oct 22;9(11):2342.

22 Kumar-Sinha C, Tomlins SA, Chinnaiyan AM. Recurrent gene fusions in prostate cancer. Nat Rev Cancer. 2008 Jul;8(7):497-511.

23 Bubendorf L. Words of wisdom. re: aberrant ERG expression cooperates with loss of PTEN to promote cancer progression in the prostate. Eur Urol. 2009 Nov;56(5):882-3.

24 Font-Tello A, Juanpere N, de Muga S, Lorenzo M, Lorente JA, Fumado L, et al. Association of ERG and TMPRSS2-ERG with grade, stage, and prognosis of prostate cancer is dependent on their expression levels. Prostate. 2015 Aug 1;75(11):1216-26.

25 Schmitz M, Grignard G, Margue C, Dippel W, Capesius C, Mossong J, et al. Complete loss of PTEN expression as a possible early prognostic marker for prostate cancer metastasis. Int J Cancer. 2007 Mar 15;120(6):128492.

26 Lotan TL, Carvalho FL, Peskoe SB, Hicks JL, Good J, Fedor H, et al. PTEN loss is associated with upgrading of prostate cancer from biopsy to radical prostatectomy. Mod Pathol. 2015 Jan;28(1):128-37.

27 Halvorsen OJ, Haukaas SA, Akslen LA. Combined loss of PTEN and p27 expression is associated with tumor cell proliferation by Ki67 and increased risk of recurrent disease in localized prostate cancer. Clin Cancer Res. 2003 Apr;9(4):1474-9.

28 Antonarakis ES, Keizman D, Zhang Z, Gurel B, Lotan TL, Hicks JL, et al. An immunohistochemical signature comprising PTEN, $\mathrm{MYC}$, and Ki67 predicts progression in prostate cancer patients receiving adjuvant docetaxel after prostatectomy. Cancer. 2012 Dec 15;118(24):6063-71.

29 Hockenbery D, Nuñez G, Milliman C, Schreiber RD, Korsmeyer SJ. Bcl-2 is an inner mitochondrial membrane protein that blocks programmed cell death. Nature. 1990 Nov 22; 348(6299):334-6.
30 Colombel M, Symmans F, Gil S, O’Toole KM, Chopin D, Benson M, et al. Detection of the apoptosis-suppressing oncoprotein bc1-2 in hormone-refractory human prostate cancers. Am J Pathol. 1993 Aug;143(2):390-400.

31 Raffo AJ, Perlman H, Chen MW, Day ML, Streitman JS, Buttyan R. Overexpression of bcl2 protects prostate cancer cells from apoptosis in vitro and confers resistance to androgen depletion in vivo. Cancer Res. 1995 Oct 1; 55(19):4438-45.

32 Borre M, Stausbol-Gron B, Nerstrom B, Overgaard J. Immunohistochemical BCL-2 and Ki67 expression predict survival in prostate cancer patients followed expectantly. Prostate Cancer Prostatic Dis. 1998 Sep;1(5):268-75.

33 Keshgegian AA, Johnston E, Cnaan A. Bcl-2 oncoprotein positivity and high MIB-1 (Ki$67)$ proliferative rate are independent predictive markers for recurrence in prostate carcinoma. Am J Clin Pathol. 1998 Oct;110(4): 443-9.

34 Mertz KD, Horcic M, Hailemariam S, D'Antonio A, Dirnhofer S, Hartmann A, et al. Heterogeneity of ERG expression in core needle biopsies of patients with early prostate cancer. Hum Pathol. 2013 Dec;44(12):272735.

35 Lotan TL, Gurel B, Sutcliffe S, Esopi D, Liu W, $\mathrm{Xu}$ J, et al. PTEN protein loss by immunostaining: analytic validation and prognostic indicator for a high risk surgical cohort of prostate cancer patients. Clin Cancer Res. 2011 Oct 15;17(20):6563-73.

36 Richardsen E, Andersen S, Al-Saad S, Rakaee M, Nordby Y, Pedersen MI, et al. Evaluation of the proliferation marker Ki-67 in a large prostatectomy cohort. PLoS One. 2017; 12(11):e0186852.

37 Epstein JI, Egevad L, Amin MB, Delahunt B, Srigley JR, Humphrey PA; Grading Committee. The 2014 international society of urological pathology (isup) consensus conference on gleason grading of prostatic carcinoma: definition of grading patterns and proposal for a new grading system. Am J Sur Pathol. 2016 Feb;40(2):244-52.

38 Lotan TL, Tomlins SA, Bismar TA, Van der Kwast TH, Grignon D, Egevad L, et al. Report from the international society of urological pathology (ISUP) consultation conference on molecular pathology of urogenital cancers. I. Molecular biomarkers in prostate cancer. Am J Surg Pathol. 2020 Jul;44(7):e15-29.

39 Kreipe H. [Ki67: biological intertumor variance versus variance of assay]. Pathologe. 2018 Dec;39(Suppl 2):272-7.

40 Senkus E, Kyriakides S, Ohno S, Penault-Llorca F, Poortmans P, Rutgers E, et al. Primary breast cancer: ESMO clinical practice guidelines for diagnosis, treatment and follow-up. Ann Oncol. 2015 Sep;26(Suppl 5):v8-30.

41 Duffy MJ, Harbeck N, Nap M, Molina R, Nicolini A, Senkus E, et al. Clinical use of biomarkers in breast cancer: updated guidelines from the European Group on Tumor Markers (EGTM). Eur J Cancer. 2017 Apr;75:284-98. 